\title{
ACCURACy of IrRigation EfFiciency Estimates
}

\author{
By A. J. Clemmens ${ }^{1}$ and C. M. Burt, ${ }^{2}$ Members, ASCE
}

\begin{abstract}
Evaluation of actual irrigation system performance should rely on an accurate hydrologic water balance over the area considered. In a companion paper, water uses are categorized as consumptive or nonconsumptive, and beneficial or nonbeneficial. Real performance is based on water uses over a specified period of time, rather than observation of a single irrigation event (with associate potential, but not yet actual, consumptive and/or beneficial uses). Once the components in the water balance have been determined, it is shown that the accuracy of irrigation performance parameters can be determined from the accuracy of the components in the water balance, using standard statistical procedures. Accuracy is expressed in terms of confidence intervals. Equations, procedures, and examples are provided for making these calculations. It is recommended that confidence intervals be included in all reporting of irrigation system performance parameters.
\end{abstract}

\section{INTRODUCTION}

The ASCE Task Committee on Describing Irrigation Efficiency and Uniformity has attempted to define irrigation performance measures from a hydrologic standpoint (Burt et al. 1997). For any system the lateral and vertical boundaries are precisely defined. The areal extent of the system can be on any scale (e.g., field, farm, district, or project), depending on the intent of the evaluation. Similarly, the vertical extent can include only the crop root zone, or may also include a shallow ground water aquifer or the entire ground water aquifer, depending on the intent or the hydrologic setting. Then, a water balance is applied to the inflows and outflows from the system (Fig. 1). Irrigation performance measures are defined in terms of the ultimate destination (i.e., use) of the applied irrigation water. Irrigation water that enters and leaves the boundaries (i.e., representing a particular use) is separated from the other inflows and outflows (e.g., the amount of precipitation, other surface water flow, and ground water flow, etc.).

Another important consideration of the ASCE Task Committee in viewing irrigation system performance was separating consumptive use from beneficial use. Some water is consumed nonbeneficially, whereas some water that is beneficially used is not consumed (i.e., it remains within the hydrologic system as a liquid). This suggests the development of terms or symbols for describing the hydrologic balance (i.e., consumed versus nonconsumed) that are different from those for describing irrigation performance (i.e., beneficially versus nonbeneficially used). Furthermore, one can also define terms that describe proper management of both irrigation water and precipitation, or terms that describe proper management of any other portion of the water balance of interest.

Because of the large amount of water consumed by irrigated agriculture and the potential environmental degradation resulting from its drainage, there is considerable interest in defining the performance of such systems, with the hope that this will lead to improvements in overall water management. Once irrigation water is applied to a field, it becomes part of a new hydrologic system and its ultimate destination is difficult to trace. Precise measurement of the actual amount of irrigation water used by crops over a large area is difficult. Burt et al.

${ }^{1}$ Res. Hydr. Engr., U.S. Water Conservation Lab., USDA/ARS, 4331 E. Broadway, Phoenix, AZ 85040.

${ }^{2}$ Dir., Irrig. Training and Res. Ctr., California Polytechnic State Univ., San Luis Obispo, CA 93407.
(1997) discuss many of the difficulties in making estimates of this water use. Furthermore, deep percolation and/or shallow ground water flow in or out of the field root zone is very difficult to measure. Separating rainfall contributions from irrigation contributions further compounds the difficulty in determining the fate of the applied irrigation water. Because irrigation system performance is so tied to the hydrologic system in most cases, our knowledge of actual irrigation system performance is imprecise.

In this paper we focus on the accuracies of the estimates of the various components in the water balance and their influence on the accuracy of the resulting performance measures. Equations and procedures are presented for computing confidence intervals for the irrigation performance measures defined by the ASCE Task Committee. The same methodology can also be applied to performance measures based on other components of the water balance. This paper amplifies many of the concepts presented in the task committee report.

\section{HYDROLOGIC WATER BALANCE}

The definition of boundaries is extremely important to this hydrologic-balance approach for defining system performance. The lateral boundaries are often easy to define for a particular political entity (e.g., an irrigation district). However, such political boundaries may not be convenient for defining a hydrologic water balance. Often a water balance based on geographic boundaries is more feasible, even though more complexity is involved in separating the political entities within such boundaries. The difficulty is defining the flow of

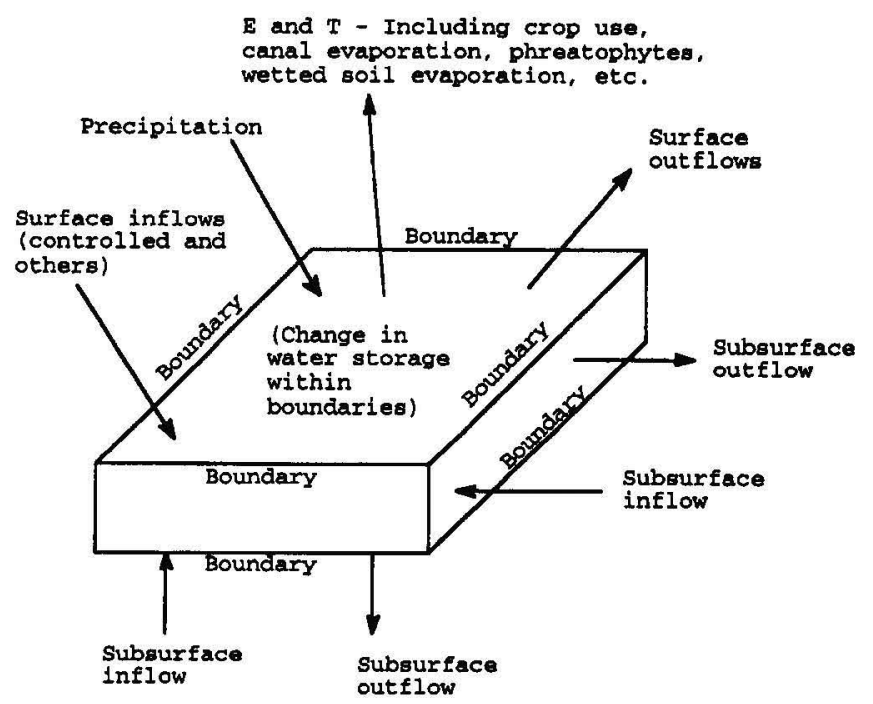

FIG. 1. Components of Simplifled Water Balance within Defined Boundarles 
water across political boundaries when there is no natural geographic boundary that restricts the flow so that it can be conveniently measured (e.g., measuring ground water flow between neighboring irrigation districts sharing the same aquifer may be very difficult and expensive).

The vertical boundaries are often more difficult to establish. For measurements on a field scale, the bottom of the root zone is generally used as the lower boundary. However, there may be extreme difficulty in estimating the amount of deep percolation. The presence of a shallow water table complicates the situation since water can be taken up from the ground water by the plant roots, and since shallow water inflow and outflow are very difficult to determine on a small scale such as a field.

The ASCE Task Committee determines performance in terms of water leaving the boundaries of the system. That is, when the water leaves, it is grouped into a category of use (consumed or nonconsumed and beneficial or nonbeneficial), but not before. For larger scale systems (i.e., larger than field scale), water is often recirculated within the boundaries of the system. Such water should not be double-counted in a water balance for determining performance measures. It is simply considered recirculating or in storage. Changes in storage must be taken into account when inflow and outflows over a specified period of time do not match.

Where ground water is pumped for irrigation and irrigation deep percolation returns to the same ground water aquifer, the ground water aquifer should be included within the boundaries of the system. For some geographic settings, this makes determination of a hydrologic balance very difficult, since natural ground water recharge and ground water inflow may be very difficult to estimate. Ground water systems with multiple aquifers that are partially connected may further complicate the hydrologic balance.

Such difficult studies are often outside the interest of agriculturalists. A common alternative to actual measurement is to use deep percolation or ground water flow as the remainder (closure term) in the water balance calculations. This is feasible, in many cases, but requires that more accurate estimates be made of consumptive uses, which can also be difficult in a diverse landscape.

\section{UNCERTAINTY AND CONFIDENCE INTERVALS}

Every measurement of a nondiscrete quantity, such as water volume, contains an element of uncertainty, regardless of the variable and the method of measurement. This applies to all methods for estimating the water sources and destinations in the water-balance diagrams. Confidence intervals are a standard statistical approach for describing the uncertainty asso-

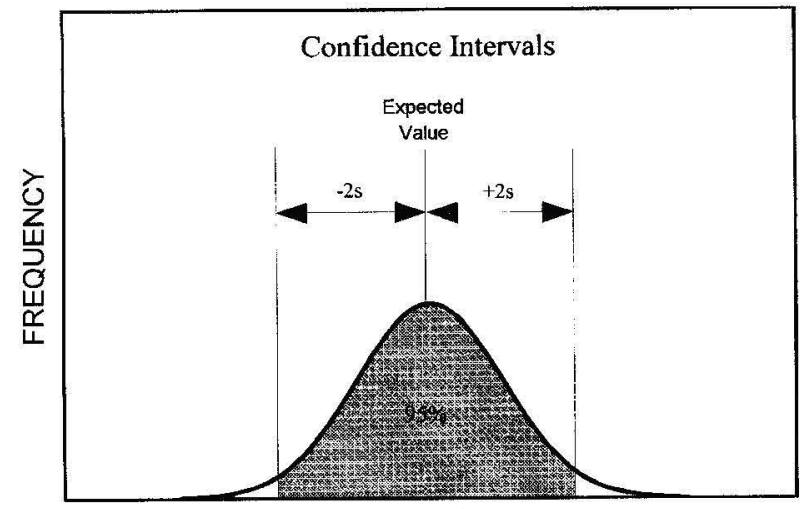

VALUE

FIG. 2. Normal Distribution of Values Showing $95 \%$ Confidence Interval ciated with the value of each water quantity. The $95 \%$ confidence interval is commonly used in statistics to represent the degree of certainty for a variable of interest. It represents the range within which we are $95 \%$ certain that the true value of that variable lies. For a normal distribution of measurements, the $95 \%$ confidence interval represents approximately \pm 2 standard deviations (Fig. 2). Here, we define the confidence interval $(\mathrm{CI})$ as \pm 2 standard deviations, regardless of the distribution type. For other distributions (e.g., log-normal, beta, etc.), this confidence interval may represent a percentage slightly different from $95 \%$.

Errors in measurements include errors in the device calibration, errors in reading, errors in installation or zeroing, and so forth, and can be either systematic or random. Random errors are typically normally distributed. Repeated measurements at a given site can reduce the impact of random errors, since for a very large sample these random errors approach 0 . The accuracy of a water volume determined from multiple flow rate measurements can be improved by more frequent measurement (i.e., it is related to number of samples), if the measurement error is random. However, repeated measurements of a given flow or water quantity do not remove systematic errors, and the inaccuracy caused by systematic errors is not related to the number of samples taken. Systematic errors, for example, from installation, are constant for one installation but may vary randomly from installation to installation. Such errors may be unknown for any given installation, but when considering the combined influence of installations at many sites, they are often treated as random errors, again normally distributed. However, the average value for measurements at many similar sites may still contain a systematic error.

For many quantities of interest, more than one measurement is needed to determine a numerical value; for example, a quantity of interest may consist of two other components that are added, subtracted, multiplied, or divided. Standard statistical equations are given subsequently for determining the uncertainty of the result, given the uncertainty of the individual measurements. The associated statistics can also be used to determine which quantities contribute most to the uncertainty of the desired performance measure and to guide efforts to reduce uncertainty.

\section{Statistical Relationships}

In this context we are trying to estimate the one true value of some variable (i.e., a water volume) that might be estimated by summing (e.g., integrating) several measurements or that might have several individual estimates (or a distribution of possible values). Classical statistics typically deal with the distribution of a population and measures of that population such as the mean. Here we are interested in the expected value of a variable, which, in reality, has one true value, and its distribution of possible values. It does not matter how this variable is estimated for other statistics (i.e., it could be a sum, a mean, a product, a quotient, the result of integration, etc.). The statistical relationships and equations for dealing with the expected value of a variable and the mean of a population are identical. Thus, when we refer to the expected value, we use $m$ in the notation to conform to the standard statistical notation.

The standard deviation, $s$, is a standard statistical measure of variability. It describes the spread of the distribution of values. The variance is the square of the standard deviation. The variance for the variable $y$, for example, can be estimated from a sample of size $n$ with

$$
s_{y}^{2}=\frac{\sum_{i=1}^{n}\left(y_{i}-m_{y}\right)^{2}}{n \cdot 1}
$$


The coefficient of variation of $y, C V_{y}$, is the standard deviation $s_{y}$ divided by the expected value, $m_{y}$

$$
C V_{y}=\frac{s_{y}}{m_{y}}
$$

Formally, the confidence interval for the true value of $y$ is defined here as

$$
m_{y}-2 s_{y} \leq y \leq m_{y}+2 s_{y}
$$

However, the confidence interval is often expressed in terms of the variation around the expected value, either in terms of the standard deviation or in terms of the coefficient of variation

$$
C l= \pm 2 s \text { or } C I= \pm 2 C V
$$

The latter gives a measure of relative accuracy and has no units (i.e., $C I$ relative to the magnitude of the expected value). The $C V$ and $C I$ are often expressed as a percent, particularly when they represent an accuracy of measurement.

\section{Combination of Variance Equations}

When several component parameters contribute to the variation of a parameter of interest, we use the notation $y_{0}$ for the combined result and $y_{1}, y_{2}, y_{3}, \ldots$ to represent the components. For simplicity the symbol $y$ is dropped from the subscripts for $m, s, C V$, and so on, so that $m_{0}$, for example, represents the expected value of $y_{0}$. The following combination of variance equations can be found in Mood et al. (1974). These equations assume only that the variables are random; the variables need not be normally distributed (i.e., one equation might follow a log-normal distribution while another follows a beta distribution).

\section{Addition}

When adding several quantities of interest, for example, $y_{0}$ $=y_{1}+y_{2}$, the expected value of the sum is just the sum of the component expected values

$$
m_{0}=m_{1}+m_{2}
$$

The variance is found from

$$
s_{0}^{2}=s_{1}^{2}+s_{2}^{2}+2 s_{12}^{2}
$$

where $s_{12}^{2}=$ covariance of $y_{1}$ and $y_{2}$, defined as

$$
s_{12}^{2}=\frac{\sum_{i=1}^{n}\left(y_{1_{i}}-m_{1}\right)\left(y_{2_{i}}-m_{2}\right)}{n-1}
$$

If the quantities are independent, the covariance is 0 , the last term in (6) is eliminated, and the coefficient of variation is found from

$$
C V_{0}^{2}=\frac{m_{1}^{2}}{m_{0}^{2}} C V_{1}^{2}+\frac{m_{2}^{2}}{m_{0}^{2}} C V_{2}^{2}
$$

\section{Multiplication}

We can also combine the influences of several factors that are multiplied to obtain the combination (e.g., $y_{0}=y_{1} y_{2}$ ). The expected value of $y_{0}$ can be found from

$$
m_{0}=m_{1} m_{2}+s_{12}^{2}
$$

Note that if $y_{1}$ and $y_{2}$ are not independent, then the expected value is not the product of the component expected values. That is, $m_{0}=m_{1} m_{2}$ only if $y_{1}$ and $y_{2}$ are independent.

The variance of the product can be found from

$$
s_{0}^{2}=m_{2}^{2} s_{1}^{2}+m_{1}^{2} s_{2}^{2}+s_{1}^{2} s_{2}^{2}+2 m_{1} m_{2} s_{12}^{2}
$$

in which higher-order terms have been ignored. If $y_{1}$ and $y_{2}$ are independent, the coefficient of variation for $y_{0}$ is

$$
C V_{0}^{2}=C V_{1}^{2}+C V_{2}^{2}+C V_{1}^{2} C V_{2}^{2}
$$

\section{Division}

The expected value and variance of a quotient of two variables, each with its own distribution, for example, $y_{0}=y_{1} / y_{2}$, cannot be computed exactly, even if the correlation between $y_{1}$ and $y_{2}$ is known. Approximate equations (Mood et al. 1974) are

$$
\begin{aligned}
& m_{0} \approx \frac{m_{1}}{m_{2}}\left(1+\frac{s_{2}^{2}}{m_{2}^{2}}-\frac{s_{12}^{2}}{m_{1} m_{2}}\right) \\
& s_{0}^{2} \approx \frac{m_{1}}{m_{2}}\left(\frac{s_{1}^{2}}{m_{1}^{2}}+\frac{s_{2}^{2}}{m_{2}^{2}}-\frac{2 s_{12}^{2}}{m_{1} m_{2}}\right)
\end{aligned}
$$

Note that for division, the expected value of the quotient is not the quotient of the expected values, even if $y_{1}$ and $y_{2}$ are independent, due to the term $s_{2}^{2} / m_{2}^{2}$. However, this term is usually quite small. If $y_{1}$ and $y_{2}$ are independent and this term is ignored, a conservative estimate for the coefficient of variation for $y_{0}$ can be found from

$$
C V_{0}^{2} \approx C V_{1}^{2}+C V_{2}^{2}
$$

\section{IRRIGATION PERFORMANCE MEASURES}

Having a firm understanding of the hydrologic water balance is an important first step in assessing irrigation performance. Once the components of the water balance are quantified, one can make rational decisions about the appropriateness of the water uses and whether they have a positive or negative effect on crop production, the economic health of the region, the environment, or any other issues of importance. Any number of performance measures can be constructed from these water-balance components. For illustrative purposes this paper deals with the main performance measures associated with irrigation. More specifically, two irrigation system performance indicators proposed by the ASCE Task Committee are discussed.

The first indicator, irrigation efficiency, $I E$, deals with water that was beneficial for crop production

$$
\begin{aligned}
I E & =\frac{\text { volume of irrigation water beneficially used }}{\text { volume of irrigation water applied }-\Delta \text { storage of irrigation water }} \\
& \times 100 \%
\end{aligned}
$$

where $\Delta$ storage refers to change in storage of the irrigation water within the boundaries. This change in storage represents irrigation water inflow that has not left the boundaries and is therefore neutral with regard to beneficial or nonbeneficial use. (Irrigation water that was initially in storage and later leaves the boundaries also represents a change in storage.) The numerator is really the sum of the beneficial uses, whereas the denominator is the sum of the beneficial uses plus the sum of the nonbeneficial uses.

The second indicator, irrigation consumptive use coefficient, $I C U C$, deals with the fraction of water actually consumed (i.e., no longer liquid water)

$$
\begin{aligned}
& \text { ICUC }=\frac{\text { volume of irrigation water consumptively used }}{\text { volume of irrigation water applied }-\Delta \text { storage of irrigation water }} \\
& \times 100 \%
\end{aligned}
$$

The denominator is the sum of the water consumed beneficially plus the sum of the water consumed nonbeneficially. Determining numerical values for these two indicators requires 


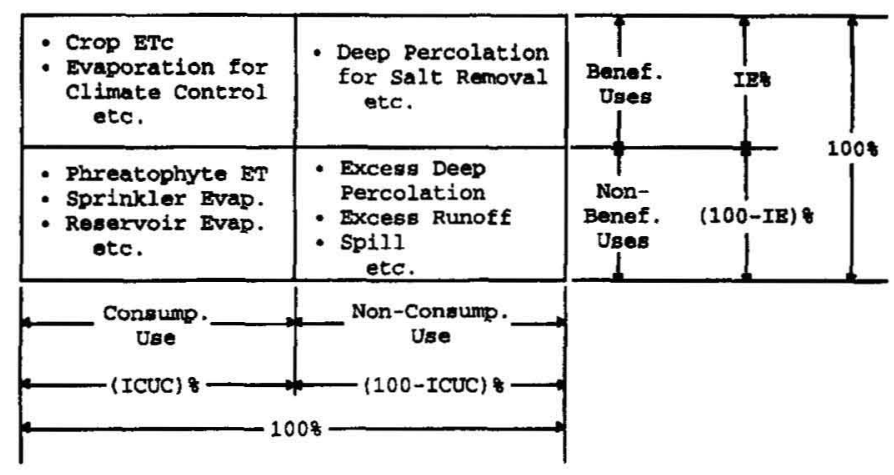

FIG. 3. Division between Consumptive and Nonconsumptive Uses Is Distinct from Division between Beneflclal and Nonbeneficial Uses

estimates for each component in the water balance. The difference between $I E$ and ICUC is demonstrated in Fig. 3.

\section{ESTIMATING WATER USES}

For the purposes of this discussion, water uses are grouped into four categories - representing combinations of consumptive/nonconsumptive and beneficial/nonbeneficial. For each quantity of interest, three methods can be used to estimate its numerical value

- Direct measurement-for example, with an accumulating water meter

- Indirect measurement - for example, estimates of evapotranspiration (ET) from weather data and crop coefficients

- Mass balance closure - that is, the remainder in a water or ion balance

Direct measurements are usually preferred, but not always feasible. Indirect measurements require some assumptions that may require field verification. For a water balance there can only be one closure term (or a group of related quantities). Obtaining an accurate estimate of the closure term requires good estimates of all other terms in the water balance. The accuracy of the remainder can be estimated from the accuracy of the other terms with the preceding equations, as will be demonstrated subsequently.

\section{Quantifying Consumptive Beneficial Uses}

In many irrigated areas crop consumptive use is the largest consumptive use and the largest beneficial use of water. Crop consumptive use is primarily crop evapotranspiration, $E T_{c}$. Thus, $E T_{c}$ usually receives the primary focus of attention in any water-balance study. A major problem with determining $E T_{c}$ over large areas is that it can be highly variable, not only from differences in vegetation type but also from variations in $E T_{c}$ within one field.

There are several ways to estimate crop consumption. The primary ones, however, are the following.

Direct Measurement. There are a few specialized procedures for measuring evapotranspiration, more or less, directly. For example, the eddy-correlation method measures the flux of vapor above the surface. The Bowen-ratio approach combines this measurement with other atmospheric measurements and an energy balance. Such methods require significant instrumentation to obtain essentially a point measurement in space and time. Such point measurements may be difficult to extrapolate to large areas where evapotranspiration is highly variable and to an irrigation season.

Indirect Measurement. Weather-based methods are the most common approach for estimating crop evapotranspira- tion. First, atmospheric measurements are used to determine hourly or daily reference evapotranspiration, $E T_{r}$. Then crop coefficients are applied to account for differences in crop properties and growth stages. These crop coefficients are ideally a combination of basal crop coefficients derived from field experiments during relatively dry soil surface conditions, modified for the moisture content at the soil surface and in the root zone. Different approaches to estimating $E T$, produce estimates that may differ by more than $10 \%$ (Jensen et al. 1990; Ley et al. 1994). Crop coefficients depend on the method for computing reference evapotranspiration. These crop coefficients, even with the same reference, can vary with climatic conditions. Relatively accurate crop coefficients are available for the major crops such as wheat, corn, and cotton, but for many crops they are either nonexistent or based on very limited data. Furthermore, this approach generally assumes that crop ET is uniform over the entire field and not limited by soil moisture, salinity, insect damage, and so forth (e.g., no local plant stress). The result is that these methods are not precise and can contain significant error. Other indirect measurement methods and their associated difficulties are discussed in Burt et al. (1997).

Mass Balance Closure. A water balance can be used to estimate the unmeasured water uses, which can be done at a field, farm, district, or project scale. If estimates of surface and subsurface inflow and outflow and change in storage are made, the remainder in the water balance is the total evapotranspiration from the area, one component of which is the crop $E T$. To determine only the portion of ET for the crop and for the irrigation water, estimates of $E T$ for all the other $E T$ components must be made. These might include crop $E T$ from rainfall, weed $E T$, canal and reservoir evaporation, soil evaporation, windbreak and phreatophyte $E T$, etc. Estimating the aerial extent and $E T$ rate from such areas on a district scale can be quite difficult. More details on problems with applying any of these methods are given in the ASCE Task Committee paper (Burt et al. 1997).

\section{Quantifying Nonconsumptive Beneficial Uses}

The main nonconsumptive beneficial use is deep percolation water that is needed to leach salts from the soil. Water for leaching is needed in arid areas even after initial reclamation of the soil since salts dissolved in the irrigation water are left behind when the water evapotranspires. The leaching requirement, $L R$, is defined as

$$
L R=\frac{\text { volume of irrigation water needed for leaching }}{\text { volume of irrigation water needed for } E T_{c} \text { and leaching }}
$$

The volume of water that is potentially beneficial for leaching (required-beneficial-deep percolation) is then

$$
V_{r b d p}=\frac{L R \times E T_{c_{i w}}}{1-L R}
$$

where $E T_{c_{t w}}$ is the $E T_{c}$ of the irrigation water, expressed as a volume.

The leaching requirement varies with the quality of the irrigation water and the sensitivity of the particular crop to soil salinity. Several equations have been suggested for determining the leaching requirement (e.g., Rhodes 1974). These equations typically define the amount of deep percolation water needed to maintain soil salinity at a given level. They regularly do not include reclamation leaching and often ignore the contribution of rainfall to leaching. These equations are beyond the scope of the current paper, except to say that this is a very inexact science. Thus, the volume of water that was actually beneficial for leaching salts for a given field cannot be precisely determined. Also, because of soil nonuniformity and 


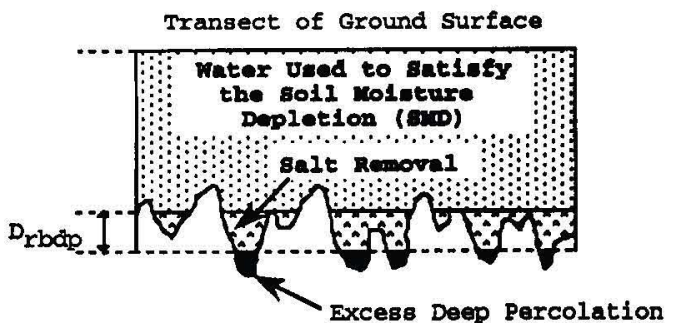

FIG. 4. Deficit Irrigation with Nonbeneficlal Deep Percolation ( $D_{\text {rbap }}=$ Depth of Required Beneficial Deep Percolation)

preferential flow, even if the irrigation system applies water with perfect uniformity, all of the leaching water likely will not be beneficial, even if the average leaching depth is less than the required leaching depth, as shown in Fig. 4 [see Burt et al. (1997) for further discussion].

Other beneficial uses include water for the following:

- Crop cooling (e.g., for quality or to alter dormancy and growth stages)

- Frost protection

- Soil preparation

- Disease and pest control

- Germination

- Maintenance of cover crops and windbreaks

Some of this water is consumed, whereas some is not. Clearly not all the water used for these purposes is justified as beneficial (e.g., applying a $100-\mathrm{mm}$ irrigation for frost control when only $30 \mathrm{~mm}$ is needed). Estimating how much of the water applied for these uses is beneficial is very difficult to determine accurately. Yet, these are real needs of crop production, and some amount of water for these purposes is essential.

\section{Quantifying Consumptive Nonbeneficial Uses}

Consumptive nonbeneficial uses are primarily excess evaporation from free water surfaces and wet soil and transpiration by plant that are nonbeneficial for crop production. This is not to say that this use of water is not beneficial for other purposes (e.g., wildlife). However, this partitioning of water separates the agricultural uses from other uses. Evaporation from supply reservoirs and irrigation canals can be estimated with energy balance approaches with reasonable accuracy. Transpiration from other vegetation within the boundaries can be difficult -both in terms of accurately knowing the area of various plants and in knowing their transpiration rates. Examples include weeds, grasses and trees along canals and drains, and so on.

\section{Quantifying Nonconsumptive Nonbeneficial Uses}

Nonconsumptive nonbeneficial uses are represented by water that leaves the boundaries of the system, but which cannot be assigned as a beneficial use. In some cases, whether the use is consumptive or nonconsumptive depends on how you draw the boundaries of the system (e.g., whether drainage channels containing phreatophytes are included or not). Water leaving the system as surface flow can be relatively easy to measure accurately, whereas deep percolation or subsurface flows are much more difficult to estimate.

\section{Quantifying Water Sources}

Surface water supplies include water from reservoirs, river diversions, or canal deliveries, and water pumped from rivers or ground water. Such water sources are generally easier to measure than the water uses. However, in many projects measurement and records are not sufficient to provide these volumes within the desired accuracy. Oftentimes flow measurement devices are either improperly installed or calibrated, nonfunctional, or missing entirely. Records of water deliveries are not always accurately maintained. In most states measurement of ground water pumping is not required and wells are simply not metered. Depending on site specific conditions, quantifying the water supply can be as difficult and expensive as measurement of the water uses.

\section{ESTIMATING CONFIDENCE INTERVALS}

For many water quantities or uses, estimates of measurement error can be made from evaluation of the methods and instruments in use. Meter specifications often give only the precision of the reading, which can be much smaller than the accuracy and does not take into account errors associated with a specific installation. Some meters provide an accuracy for a single reading but do not separate the systematic and random error components, which are needed to determine the error associated with repeated measurements. Furthermore, the accuracy of secondary devices, which translate the primary measurement device into a useful reading, can add error to the overall measurement that is often not included in the published accuracy of the primary device. In some cases periodic readings from a measuring device that measures flow rate are used to determine volume over time. This is typically done in a systematic fashion (e.g., each morning), which can also add a systematic error. Even for well-documented water measurement devices, some engineering analysis and judgment may be required to estimate the confidence interval of the measured water volume.

For many of the quantities or uses in the water balance, the values chosen are no better than educated guesses. For such uses determining the accuracy or confidence interval is very difficult. Also, for some instruments and equipment, errors are often one-sided. Examples include pyranometers and radiometers whose lenses get dirty (and thus read low), or propeller meters that turn slower as the bearings wear.

The confidence interval reflects a best estimate of the range of likely values for the quantity of interest. For quantities with limited available data, we can estimate the largest value we think is possible, and the lowest value we think is possible. That is, rather than defining the expected value and standard deviation, we define a range over which we are confident the true value will lie. This is commonly done in simulation studies, where a triangular distribution is defined based on minimum, maximum, and most likely value (Pritsker 1986). For our purposes we suggest using this range as the confidence interval. If this range is \pm 2 standard deviations, then the standard deviation is one-fourth the range.

The calculation of standard deviation and confidence interval range do not assume anything about the probability distribution. However, for different distribution types (e.g., other than Gaussian), the probability of being within \pm 2 standard deviations may not be $95 \%$ and the expected value may not be in the center of the $\mathrm{Cl}$ range. If the most likely value of one quantity is not centered on the range, then we have no way of easily determining where the confidence interval for the final value is relative to the expected value. For example, if the confidence interval range is $4( \pm 2)$ and the expected value is 10 , then if it is centered, the confidence interval is $8-12$. However, it may also be $9-13$ or $7.5-11.5$. For now we recommend assuming that the most likely value is in the middle of the range. In reality the confidence intervals provided with this methodology are simply an estimate.

The statistical procedures demonstrated in the following examples allow us to determine the influence of the accuracy of 
any particular quantity on the accuracy of the final result. For some of the smaller quantities in the water balance, whether the confidence interval is very wide or very narrow has little influence on the accuracy of the final result, and a reasonable guess is sufficient. The larger quantities typically need to be determined very accurately.

\section{EXAMPLES}

\section{Example 1. Simplified Example for Estimating IE Confidence Intervals}

Consider a seasonal evaluation of a field with inflows and beneficial uses, and their associated accuracies as given in Table 1 . The beneficial leaching for salt removal in Table 1 was based on a leaching requirement of 0.07 , knowledge that there was no underirrigation, and the assumption that no rainfall ended up as deep percolation. The volume of leaching water is found from (18). The confidence interval for the volume of beneficial leaching was assumed to be $\pm 30 \%$. The coefficient of variation of the ratio $L R /(1-L R)$ can be taken as

$$
C V_{\text {ratio }}=\left(1+\frac{L R}{1-L R}\right) C V_{L R}
$$

which can be derived from (7) and (13), assuming that $L R$ and $(1-L R)$ are $100 \%$ correlated and are a simplified form of (12). With $C V_{L R}=0.15$ and $L R /(1-L R)=0.075$, (19) gives $C V_{\text {ratio }}=0.161$. Since the volume of beneficial leaching is obtained by multiplying this ratio by the beneficial $E T,(11)$ is used to compute the $C V$ for the beneficial leaching, which is 0.166 . This gives a confidence interval of \pm 0.333 or $\pm 33.3 \%$, as shown in Table 1 .

The other beneficial uses were assumed to range from 0 to $2 \%$ of the beneficial ET. This was assumed to represent the confidence interval, giving an expected value of $1 \%$ and a $C I$ $= \pm 100 \%$. The accuracies given in Table 1 are typical of engineering studies of actual beneficial uses, based on careful inflow and outflow measurements [see Burt et al. (1997) for further discussion].

Find. The volume of beneficial use and $I E$, and their associated CIs. First assume that these volumes are all independently measured, then assume that all beneficial uses are related to beneficial $E T$.

Solution with Independent Estimates. The volume of beneficial use is $6,000+450+60=6,510 \mathrm{~m}^{3}$. The variance of beneficial uses is found from (6), assuming these uses were independently estimated

$$
s_{B U}^{2}=240^{2}+75^{2}+30^{2}
$$

which gives $s_{B U}^{2}=64,125 \mathrm{~m}^{6}$, or $s_{B U}=253 \mathrm{~m}^{3}$, resulting in a confidence interval of $\pm 2 s_{B U}= \pm 507 \mathrm{~m}^{3}$, or a range of $6,005-7,019 \mathrm{~m}^{3}$. The confidence interval expressed in terms

TABLE 1. Example Data for Computing Confidence Intervals for IE

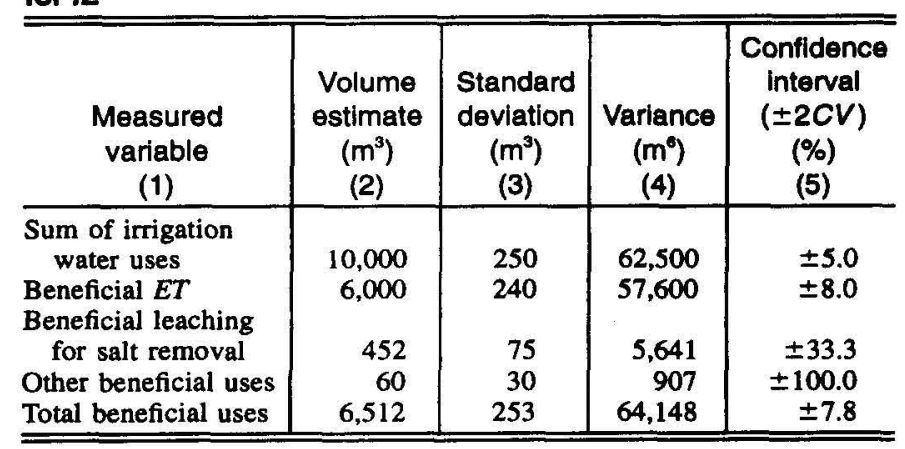

of the coefficient of variation is $\pm 7.8 \%$. The variances in column 4 of Table 1 indicate the relative influence of the different beneficial use components on the variance of the total beneficial use. Note that the large uncertainties associated with the smaller volumes do not have much influence on the confidence interval of the total. Also, when several independent random numbers are summed, the accuracy of the total can be better than any of the components (i.e., the $\mathrm{Cl}$ for beneficial $E T$ was $\pm 8.0 \%$, and for total beneficial use was $\pm 7.8 \%$ ).

If the beneficial uses and net irrigation water uses are estimated independently, the expected value of $I E$ is computed from (12), giving

$$
m_{I E}=\frac{6,512}{10,000}\left(1+\frac{250^{2}}{10,000^{2}}\right) \times 100 \%
$$

or $65.2 \%$. (For division the expected value is actually affected by the accuracy of the denominator because the influence of the denominator on the value of the quotient is highly nonlinear.) The variance and standard deviation are found from (13), or

$$
s_{I E}^{2}=\left(\frac{6,512}{10,000}\right)^{2}\left[\left(\frac{253}{6,512}\right)^{2}+\left(\frac{250}{10,000}\right)^{2}\right] \times 100 \%
$$

which gives $s_{I E}=3.0 \%$. The confidence interval for the estimated irrigation efficiency is thus $\pm 6.0 \%$, for a range of 59 $71 \%$. This wide range is typical of attempts at trying to precisely define $I E$ under field conditions.

Solution with Dependent Estimates. If all three beneficial uses are directly related to $E T_{c-i w}$, then an estimate of the $\mathrm{CI}$ of the total cannot be made by (6) unless the covariances are known. In this case the total beneficial uses are

$$
B U_{\text {Total }}=E T_{c_{i w}}\left(1+\frac{L R}{1-L R}+\frac{B U_{\text {ocher }}}{E T_{c_{\text {tw }}}}\right)
$$

To avoid computing covariances, we can evaluate the $C I$ for the sum inside the parentheses with (6) and then evaluate the $\mathrm{CI}$ for the product of $E T_{c_{i w}}$ and this sum with (11).

The sum in the parentheses of (23) is 1.085 . The $C V$ for this sum is computed from the standard deviation of the total

$$
s^{2}=0^{2}+(0.161 \times 0.075)^{2}+(0.50 \times 0.01)^{2}
$$

giving $s=0.013$ and $C V=0.013 / 1.085=0.0121$. Combining this with the $C V$ for the beneficial uses of 0.04 with (11) gives $C V_{B U}=0.042$, or a confidence interval of $8.4 \%$, rather than the $7.8 \%$ computed with independent components. Using the foregoing procedures gives a confidence interval for $I E$ of $\pm 6.4 \%$, rather than $6.0 \%$ when estimates were assumed to be independent.

\section{Example 2. Detailed Example of Project Water Budged}

Data for this example were taken from Styles (1993) and are based on a study done for the Imperial Irrigation District, located in southern California. Styles made estimates of all the major components for a hydrologic water balance for the years 1987-92. In this example we use Styles's estimates of these water-balance components for the year 1987. This example is for illustrative purposes and no attempt was made to correct errors or omissions from that report. We have assigned rough estimates for the accuracy of the various water volumes reported (Styles 1993). These are considered potential systematic errors (most quantities were based on a large number of measurements such that the effects of random errors were minimized) and are not meant to be definitive. For this example we only consider the division between consumptive and non- 
consumptive uses of irrigation water and do not attempt to determine beneficial and/or reasonable uses. Furthermore, this example is intended to demonstrate the procedures rather than to determine definitive performance values.

Styles (1993) performed a water balance on the entire valley, including the underlying ground water aquifers. The major inflows and outflows are measured, and the change in storage was assumed to be negligible due to the unique hydrologic conditions. Table 2 shows the estimated volume of inflow for the year 1987. Canal inflow represents the flow into the irrigated area from the All-American Canal. Colorado River water diverted into the canal and delivered to other users or lost to seepage and evaporation along the way is not included (i.e., Table 2 includes only the water that reaches the irrigated area). The accuracy of this volume is based on details not shown here and which have a minor influence on these results. Details of the other inflows are given in Styles (1993). These other inflows have a minor influence on the accuracy of the total inflow, as can be seen by comparing the magnitudes of the variance in column 5 of Table 2 .

The major outflows from the valley are the Alamo and New River flows to the Salton Sea, a saline lake whose surface is approximately $70 \mathrm{~m}$ below mean sea level. The sea has risen over the past several decades such that most of the irrigated land that is adjacent to the sea is below the Salton Sea level and below the local river levels. Local drainage flow in this

TABLE 2. Surface and Subsurface Water Inflows, Example 2

\begin{tabular}{l|c|c|c|c}
\hline \hline \multicolumn{1}{c|}{$\begin{array}{c}\text { Category } \\
(1)\end{array}$} & $\begin{array}{c}\text { Volume } \\
(1,000 \\
\left.\text { dam }^{3}\right) \\
(2)\end{array}$ & $\begin{array}{c}\text { Confidence } \\
\text { interval } \\
(\%) \\
(3)\end{array}$ & $\begin{array}{c}\text { Standard } \\
\text { deviation } \\
(1,000 \\
\left.\text { dam }^{3}\right) \\
(4)\end{array}$ & $\begin{array}{c}\text { Variance } \\
(1,000 \\
\left.\text { dam }^{3}\right)^{2} \\
(5)\end{array}$ \\
\hline Canal inflow & 2,159 & \pm 3.6 & 39 & 1,545 \\
River inflows from & 205 & \pm 10 & 10 & 105 \\
$\quad$ Mexico & 102 & \pm 30 & 15 & 235 \\
Total rainfall & 2 & \pm 30 & 0 & 0 \\
Other surface inflows & 16 & \pm 30 & 2 & 6 \\
Subsurface inflow & 2,485 & \pm 3.5 & 43 & 1,891 \\
Total inflow & \multicolumn{4}{|l}{} \\
\hline \hline
\end{tabular}

TABLE 3. Surface and Subsurface Water Outflows, Example 2

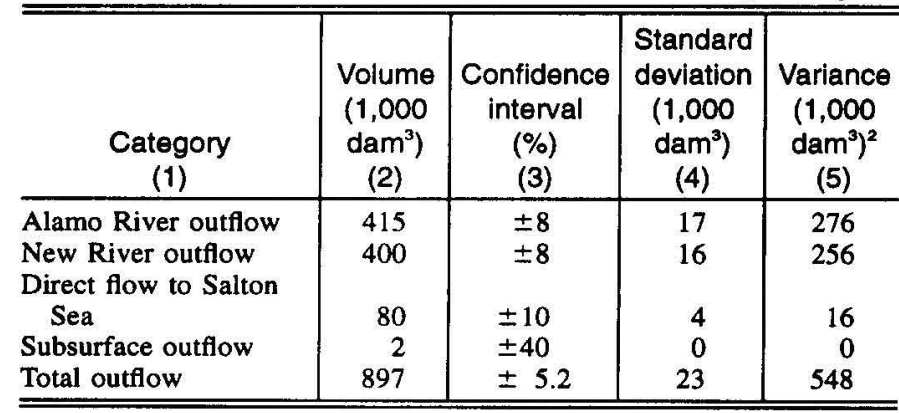

TABLE 4. Total Consumption (Primarily ET) for Area as Remainder, Example 2

\begin{tabular}{|c|c|c|c|c|}
\hline $\begin{array}{c}\text { Category } \\
\text { (1) }\end{array}$ & $\begin{array}{c}\text { Volume } \\
(1,000 \\
\left.\text { dam }^{3}\right) \\
(2)\end{array}$ & $\begin{array}{c}\text { Confidence } \\
\text { interval } \\
(\%) \\
(3) \\
\end{array}$ & $\begin{array}{c}\text { Standard } \\
\text { deviation } \\
(1,000 \\
\left.\text { dam }^{3}\right) \\
(4)\end{array}$ & $\begin{array}{c}\text { Variance } \\
(1,000 \\
\left.\text { dam }^{3}\right)^{2} \\
(5)\end{array}$ \\
\hline $\begin{array}{l}\text { Total inflow } \\
\text { Total outflow } \\
\text { Change in storage } \\
\text { Total water consumption }\end{array}$ & $\begin{array}{r}2,485 \\
-897 \\
-0 \\
1,588\end{array}$ & $\begin{array}{l} \pm 3.5 \\
\pm 5.2 \\
\text { undefined } \\
\pm 6.2\end{array}$ & $\begin{array}{r}43 \\
23 \\
4 \\
50\end{array}$ & $\begin{array}{r}1,891 \\
1,548 \\
16 \\
2,455\end{array}$ \\
\hline
\end{tabular}

area must be pumped into the sea or into one of the two rivers. Much of the soil in this area is very heavy clay, such that very little subsurface flow passes the boundary between the sea and the local aquifer (Table 3 ). With very heavy soil underlying most of the valley, subsurface flow into and out of the other boundaries is also minimal; there is no conjunctive use.

High water tables exist throughout most of the valley and tile drainage is used to remove excess water. Deep surface drains carry away tile drainage, tailwater runoff, and canal spills into the two rivers. Very little change in long-term aquifer storage exists, such that on a year to year basis overall district storage changes are minimal. Several surface reservoirs exist in the valley, but their changes in storage were not considered by Styles's water budget because their volumes are insignificant. The results of the water budget are given in Table 4, where total consumption (primarily $E T$ ) for the entire valley is the remainder.

In Table 5 water consumption is divided among the various uses, with total water consumption on irrigated land as the remainder. This consumption is further divided (Table 6 ) be-

TABLE 5. Determining Irrigated Farm Consumptlve Use by Subtracting Nonfarm Consumptive Use from Total Consumptive Use, Example 2

\begin{tabular}{|c|c|c|c|c|}
\hline $\begin{array}{c}\text { Category } \\
\text { (1) }\end{array}$ & $\begin{array}{c}\text { Volume } \\
(1,000 \\
\left.\text { dam }^{3}\right) \\
(2)\end{array}$ & $\begin{array}{c}\text { Confidence } \\
\text { interval } \\
(\%) \\
(3) \\
\end{array}$ & $\begin{array}{c}\text { Standard } \\
\text { deviation } \\
(1,000 \\
\left.\text { dam }^{3}\right) \\
(4) \\
\end{array}$ & $\begin{array}{c}\text { Variance } \\
(1,000 \\
\left.\text { dam }^{3}\right)^{2} \\
(5)\end{array}$ \\
\hline $\begin{array}{l}\text { Total water consumption } \\
\text { Canal and reservoir evap- }\end{array}$ & 1,588 & \pm 6.2 & 49 & 2,455 \\
\hline $\begin{array}{l}\text { oration } \\
\text { Consumption by } M \& I\end{array}$ & -24 & \pm 20 & 2 & 6 \\
\hline $\begin{array}{l}\text { users } \\
E T \text { from rivers, drains, }\end{array}$ & -40 & \pm 20 & 4 & 16 \\
\hline $\begin{array}{l}\text { and phreatophytes } \\
\text { Rainfall evaporation from }\end{array}$ & -73 & \pm 20 & 7 & 53 \\
\hline $\begin{array}{l}\text { nonirrigated land } \\
\text { Total water consumption }\end{array}$ & -13 & \pm 20 & 1 & 2 \\
\hline on irrigated land & 1,439 & \pm 7.0 & 50 & 2,531 \\
\hline
\end{tabular}

TABLE 6. Calculations for Irrigation Water Consumption on Irrigated Lands, Example 2

\begin{tabular}{|c|c|c|c|c|}
\hline $\begin{array}{c}\text { Category } \\
\text { (1) }\end{array}$ & $\begin{array}{c}\text { Volume } \\
(1,000 \\
\left.\text { dam }^{3}\right) \\
(2) \\
\end{array}$ & $\begin{array}{c}\text { Confidence } \\
\text { interval } \\
(\%) \\
(3) \\
\end{array}$ & $\begin{array}{c}\text { Standard } \\
\text { deviation } \\
(1,000 \\
\left.\text { dam }^{3}\right) \\
(4)\end{array}$ & $\begin{array}{c}\text { Variance } \\
(1,000 \\
\left.\operatorname{dam}^{3}\right)^{2} \\
(5)\end{array}$ \\
\hline $\begin{array}{l}\text { Total water consumption } \\
\text { on irrigated land } \\
\text { Effective precipitation } \\
\text { Noneffective rainfall } \\
\text { evaporation } \\
\text { Total irrigation-water con- } \\
\text { sumption on irrigated } \\
\text { land }\end{array}$ & $\begin{array}{r}1,439 \\
-52 \\
-23\end{array}$ & 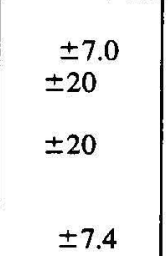 & $\begin{array}{r}50 \\
5 \\
2\end{array}$ & $\begin{array}{r}2,531 \\
27 \\
5\end{array}$ \\
\hline
\end{tabular}

TABLE 7. Calculations for Dividing Canal Water into Irrigation and Municipal and Industrial Uses, Example 2

\begin{tabular}{l|c|c|c|c}
\hline \hline & $\begin{array}{c}\text { Volume } \\
(1,000 \\
\text { Category }\end{array}$ & $\begin{array}{c}\text { Confidence } \\
\text { interval } \\
(1)\end{array}$ & $\begin{array}{c}\text { Standard } \\
\text { deviation } \\
(1,000 \\
\left.\text { dam }^{3}\right) \\
(2)\end{array}$ & $\begin{array}{c}\text { Variance } \\
(1,000 \\
\left.\text { dam }^{3}\right)^{2} \\
(5)\end{array}$ \\
\hline Canal inflow & 2,159 & \pm 3.6 & 39 & 1,545 \\
M\&I deliveries & 52 & \pm 5 & 1 & 2 \\
Canal inflow for irrigation & 2,107 & \pm 3.7 & 39 & 1,546 \\
\hline \hline
\end{tabular}


tween rainfall and irrigation water. In Table 7 canal inflow is divided among irrigation uses and municipal and industrial (M\&I) uses. Since M\&I uses are such a small percentage, we assigned all canal seepage, evaporation, and spills to the irrigation water supply.

For Tables $2-9$, and 13 variance of the total, sum, or remainder (shown in column 5) is the sum of the component variances, since all components were independently estimated [i.e., this is the solution of (6) extended to many components with a covariance of 0 ]. This variance is then used to determine the confidence interval of the result.

There are many sources of water that end up as flow in the two river systems. These river flows have two destinations: (1) Flow to the Salton Sea; and (2) evaporation from open water surfaces and evapotranspiration of phreatophytes (called the $E T$ component subsequently for simplicity). In the latter case the surface drains are included as part of the river system. An estimate for the total river inflow is given in Table 8.

Table 9 divides the irrigation water into its destinations, with the remainder representing the amount of irrigation water contributing to total river flow. With this and the other quantities

TABLE 8. Total River Inflows Based on Total Outflows, Example 2

\begin{tabular}{|c|c|c|c|c|}
\hline $\begin{array}{c}\text { Category } \\
\text { (1) }\end{array}$ & $\begin{array}{c}\text { Volume } \\
(1,000 \\
\left.\text { dam }^{3}\right) \\
(2)\end{array}$ & $\begin{array}{c}\text { Confidence } \\
\text { interval } \\
(\%) \\
(3)\end{array}$ & $\begin{array}{c}\text { Standard } \\
\text { deviation } \\
(1,000 \\
\left.\text { dam }^{3}\right) \\
(4)\end{array}$ & $\begin{array}{c}\text { Variance } \\
(1,000 \\
\left.\operatorname{dam}^{3}\right)^{2} \\
(5)\end{array}$ \\
\hline $\begin{array}{l}\text { Alamo River outflow } \\
\text { New River outflow } \\
\text { ET from rivers, drains, } \\
\text { and phreatophytes } \\
\text { Total river inflow }\end{array}$ & $\begin{array}{r}415 \\
400 \\
\\
73 \\
887\end{array}$ & $\begin{array}{l} \pm 8 \\
\pm 8 \\
\pm 20 \\
\pm 5.4\end{array}$ & $\begin{array}{r}17 \\
16 \\
\\
7 \\
24\end{array}$ & $\begin{array}{r}276 \\
256 \\
\\
53 \\
584\end{array}$ \\
\hline
\end{tabular}

TABLE 9. Determining Amount of Irrigation Water Contributing to Total River Flow, Example 2

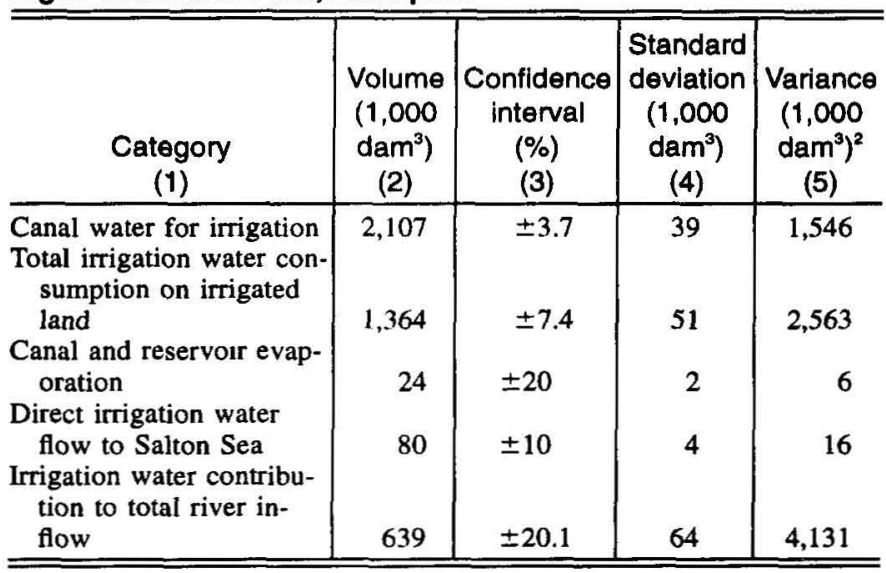

estimated by Styles (1993), there is sufficient information to determine the breakdown of water inflows that contribute to the various water outflows, as shown in Table 10 .

Still remaining is the partitioning of the irrigation water contributing to total river flow into $E T$ and flow to the Salton Sea. Here it is assumed that all sources of total river flow are partitioned into $E T$ and flow to the sea with the same percentages. The $E T$ portion is $73 / 887=8.2 \%$. Then the irrigation water contribution to the $E T$ portion is $8.2 \%$ of $629 \mathrm{dam}^{3}$, or 52 $\mathrm{dam}^{3}$. The calculation of the variance of this result is more complicated. Eqs. (14) and (11) are used to determine the coefficient of variation of the quotient (73/887) and the product $(0.082 \times 639)$, respectively, assuming the terms are independent. The results of these calculations are given in Table 11. Unfortunately, the components in these calculations are not independently estimated, since the river ET component is used to estimate the total river inflow. Fortunately, this ET component has a small impact on the variance of the total river inflow (Table 8, column 5), and the coefficient of variation of total river inflow has a small impact on the total coefficient of variation. Thus, the lack of independence in this case should have a small impact on the results and can be safely ignored. This may not always be the case, as was shown in Example 1. Applying this procedure to the remaining water inflows results in the distribution of river flows given in Table 12 .

Table 13 summarizes the consumptive uses of irrigation water inflows. Finally, the irrigation consumptive use coefficient is computed in Table 14. Eq. (14) is used to determine the coefficient of variation for the expected value of ICUC, assuming that the numerator and denominator in (14) are independent. To avoid confusion, the CIs in Table 14 are expressed as decimals rather than percentages. The expected value of ICUC is $68.3 \%$, the confidence interval is $\pm 0.080 \times$ ICUC or from $0.92 \times I C U C$ to $1.08 \times I C U C$. This translates to a confidence interval of $\pm 5.5 \%(0.080 \times 68.3 \%)$, or $63 \%<$ ICUC $<74 \%$, a range of more than $10 \%$. (Note: values in the tables for this example may contain roundoff errors.)

However, the two quantities shown in Table 14 for computing ICUC are both determined from the canal inflow given in Table 2, and thus are not independent. The equation for $I C U C$ can be modified in an attempt to reduce the dependence

$I C U C=\frac{A-B+C}{A-D} \times 100 \%=\left(1+\frac{-B+C+D}{A-D}\right) \times 100 \%$

where $A, B, C, D, E=$ different water volumes. In this case, $A=$ canal inflow (Table 2 ) and $D=$ M\&I deliveries (Table 7). Since $D$ is extremely small relative to $A$, the interdependence of the numerator and denominator is minimized. This righthand side numerator is really the (negative) volume of irrigation water not consumed. Table 15 shows the terms that make up the numerator of the quotient in the far right-hand term of (25). (These are taken directly from calculations in

TABLE 10. Disposition of Inflows and Outflows $\left(1,000 \mathrm{dam}^{3}\right)$, Example 2

\begin{tabular}{|c|c|c|c|c|c|c|c|}
\hline \multirow[b]{2}{*}{$\begin{array}{l}\text { Category } \\
\text { (1) }\end{array}$} & \multirow[b]{2}{*}{$\begin{array}{l}\text { Inflow } \\
\text { (2) }\end{array}$} & \multicolumn{6}{|c|}{ Outflow } \\
\hline & & $\begin{array}{c}E T \text { from } \\
\text { irrigated land } \\
\text { (3) }\end{array}$ & $\begin{array}{c}\text { Canal and } \\
\text { reservoir } E T \\
\text { (4) }\end{array}$ & $\begin{array}{c}\text { Noneffective soil } \\
\text { evaporation } \\
\text { (5) }\end{array}$ & $\begin{array}{c}\text { Other } \\
\text { consumption } \\
(6)\end{array}$ & $\begin{array}{l}\text { Direct flows to } \\
\text { Salton Sea } \\
\text { (7) }\end{array}$ & $\begin{array}{c}\text { Total river } \\
\text { inflows } \\
(8)\end{array}$ \\
\hline $\begin{array}{l}\text { Canal inflow for irrigation } \\
\text { Canal inflow for M\&I use } \\
\text { River inflows from Mexico } \\
\text { Rainfall on irrigated land } \\
\text { Rainfall on nonirrigated land } \\
\text { Other surface inflows } \\
\text { Subsurface inflows } \\
\text { Total }\end{array}$ & $\begin{array}{r}2,107 \\
52 \\
205 \\
83 \\
19 \\
2 \\
16 \\
2,485\end{array}$ & $\begin{array}{r}1,364 \\
52\end{array}$ & 24 & $\begin{array}{l}23 \\
13 \\
\\
36\end{array}$ & 40 & $\begin{array}{r}2 \\
82\end{array}$ & $\begin{array}{r}639 \\
11 \\
205 \\
9 \\
6 \\
2 \\
15 \\
887\end{array}$ \\
\hline
\end{tabular}


TABLE 11. Calculations for Partitioning Total Fiver Flow into ET and Flow to Salton Sea, Example 2

\begin{tabular}{c|c|c|c|c}
\hline \hline Category & $\begin{array}{c}\text { Volume } \\
(1,000 \\
\text { dam } \\
(1)\end{array}$ & $\begin{array}{c}\text { Confidence } \\
\text { interval } \\
(\%) \\
(3)\end{array}$ & $\begin{array}{c}\text { Coeffi- } \\
\text { cient of } \\
\text { variation } \\
(4)\end{array}$ & $\begin{array}{c}\text { Coeffi- } \\
\text { cient of } \\
\text { variation } \\
\text { squared } \\
(5)\end{array}$ \\
\hline $\begin{array}{c}E T \text { from rivers, drains, } \\
\text { and phreatophytes }\end{array}$ & 73 & \pm 20 & 0.10 & 0.0100 \\
$\begin{array}{c}\text { Irigation water contribu- } \\
\text { tion to total river in- } \\
\text { flow }\end{array}$ & 639 & \pm 20.1 & 0.10 & 0.0101 \\
$\begin{array}{c}\text { Total river inflow } \\
\text { Irrigation water contribu- } \\
\text { tion to } E T \text { from rivers, }\end{array}$ & 887 & \pm 5.4 & 0.03 & 0.0007 \\
and so on & 52 & \pm 29.0 & 0.014 & 0.0210 \\
\hline
\end{tabular}

TABLE 12. Disposition of Inflows with Respect to Alamo and New River Flows $\left(1,000 \mathrm{dam}^{3}\right)$, Example 2

\begin{tabular}{|c|c|c|c|}
\hline \multirow[b]{2}{*}{$\begin{array}{c}\text { Category } \\
\text { (1) }\end{array}$} & \multirow[b]{2}{*}{$\begin{array}{l}\text { Total } \\
\text { river } \\
\text { inflows } \\
(2)\end{array}$} & \multicolumn{2}{|c|}{ Outflow } \\
\hline & & $\begin{array}{l}\text { ET from rivers, } \\
\text { drains, and } \\
\text { phreatophytes } \\
\text { (3) }\end{array}$ & $\begin{array}{l}\text { River flow to } \\
\text { Salton Sea } \\
\text { (4) }\end{array}$ \\
\hline Canal inflow for irrigation & 639 & 52 & 587 \\
\hline Canal inflow for M\&I use & 11 & 1 & 10 \\
\hline River inflows from Mexico & 205 & 17 & 188 \\
\hline Rainfall on irrigated land & 9 & 1 & 8 \\
\hline Rainfall on nonirrigated land & 6 & 1 & 6 \\
\hline Other surface inflows & 2 & 0 & 2 \\
\hline Subsurface inflows & 15 & 1 & 13 \\
\hline Total & 887 & 73 & 815 \\
\hline
\end{tabular}

TABLE 13. Total Irrigation Water Consumption, Example 2

\begin{tabular}{|c|c|c|c|c|}
\hline $\begin{array}{c}\text { Category } \\
\text { (1) }\end{array}$ & $\begin{array}{c}\text { Volume } \\
(1,000 \\
\left.\text { dam }^{3}\right) \\
(2)\end{array}$ & $\begin{array}{c}\text { Confidence } \\
\text { interval } \\
(\%) \\
(3) \\
\end{array}$ & \begin{tabular}{|c|} 
Standard \\
deviation \\
$(1,000$ \\
dam $\left.^{3}\right)$ \\
$(4)$
\end{tabular} & $\begin{array}{c}\text { Variance } \\
(1,000 \\
\left.\operatorname{dam}^{3}\right)^{2} \\
(5)\end{array}$ \\
\hline $\begin{array}{l}\text { Irrigation water consump- } \\
\text { tion on irrigated land } \\
\text { Canal and reservoir } E T \\
\text { Irrigation water contribu- } \\
\text { tion to } E T \text { from rivers, } \\
\text { and so on } \\
\text { Total irrigation water con- } \\
\text { sumption }\end{array}$ & $\begin{array}{r}1,364 \\
24\end{array}$ & $\begin{array}{l} \pm 7.4 \\
\pm 20 \\
\pm 29.0 \\
\pm 7.1\end{array}$ & $\begin{array}{r}51 \\
2\end{array}$ & $\begin{array}{r}2,563 \\
6 \\
\\
57\end{array}$ \\
\hline
\end{tabular}

TABLE 14. Calculations for irrigation Consumptive Use Coefficient, ICUC, Example 2

\begin{tabular}{l|c|c|c|c}
\hline \multicolumn{1}{c|}{$\begin{array}{c}\text { Category } \\
(1)\end{array}$} & $\begin{array}{c}\text { Volume } \\
(1,000 \\
\left.\text { dam }^{3}\right) \\
(2)\end{array}$ & $\begin{array}{c}\text { Relative } \\
\text { confidence } \\
\text { interval } \\
( \pm 2 C V) \\
(3)\end{array}$ & $\begin{array}{c}\text { Coefficient } \\
\text { of } \\
\text { variation } \\
(4)\end{array}$ & $\begin{array}{c}\text { Coefficient } \\
\text { of } \\
\text { variation } \\
\text { squared } \\
(5)\end{array}$ \\
\hline $\begin{array}{c}\text { Total irrigation water } \\
\text { consumed }\end{array}$ & 1,440 & \pm 0.071 & 0.036 & 0.0013 \\
$\begin{array}{l}\text { Total irrigation water } \\
\text { supply }\end{array}$ & 2,107 & \pm 0.037 & 0.019 & 0.0003 \\
$\begin{array}{ll}\text { ICUC } & 0.683\end{array}$ & \pm 0.080 & 0.040 & 0.0016 \\
\hline \hline
\end{tabular}

Tables 2-13.) Note that in the calculations, canal and reservoir ET is first subtracted and then added. Thus its variance really should not add to the variance of the result. Also, M\&I deliveries and M\&I consumption are offsetting, leaving the much smaller M\&I return flows, with a much smaller variance. The last column in Table 15 gives the variances used in the calculations.
Table 16 shows the calculations for the confidence interval of the fraction not consumed. The confidence interval for this quantity is $\pm 0.032(0.317 \times 0.104)$. Since taking 1 minus this quantity does not influence the confidence interval (when expressed in terms of $2 s), I C U C$ has the same confidence interval, which translates to $65 \%<I C U C<72 \%$, a much narrower range than computed in the foregoing.

\section{DISCUSSION}

This detailed example is meant to show a general procedure and is not intended to reflect all possible methods to achieve a water balance or to estimate performance parameters. We do, however, intend to show how various volumes and their accuracies influence the accuracy of the final performance parameter estimates. We believe that the accuracies of water uses used in this example are typical of, and in many cases better than, the accuracies available in most irrigation districts. Furthermore, in many cases the accuracy for $I E$ may be less than that for $I C U C$, since quantifying beneficial water uses is often quite difficult (e.g., beneficial leaching and distinguishing between beneficial $E T$ and nonbeneficial evaporation). The confidence interval for ICUC in this example was about $7 \%$. Thus, reporting of more than two significant figures for irrigation performance parameters is clearly inappropriate without careful analysis of potential errors.

One of the most powerful features of this approach is the ability to determine the relative importance of the accuracy of the variables that contribute to the estimate of these performance parameters. The variance, $s^{2}$, and relative variance, $C V^{2}$, of the components gives a general indication of the importance of the accuracy of that component on the accuracy of the final estimate. Take, for example, the estimate of the accuracy of the total irrigation water consumption on irrigated land in Table 6 . The variance is dominated by one component, total water consumption on irrigated land. In Table 5 total water consumption dominates this variance $(2,455$ out of $2,531)$. Continuing to trace these back to their sources through Tables 4,3 , and 2 , we find that four components dominate the variance of irrigation water consumption on irrigated land: canal inflow (1,545), Alamo River outflow (276), New River outflow (256), and total rainfall (235), as shown in Fig. 5. These variances reflect the importance of the accuracies of these measurements on the accuracy of the final result.

When the components in the water balance and performance parameter equations are independent, the statistics presented here are straightforward to apply. However, often we do not have independent estimates of the various quantities. This can greatly increase the complexity of the analysis. When quanti-

\section{Variance Components}

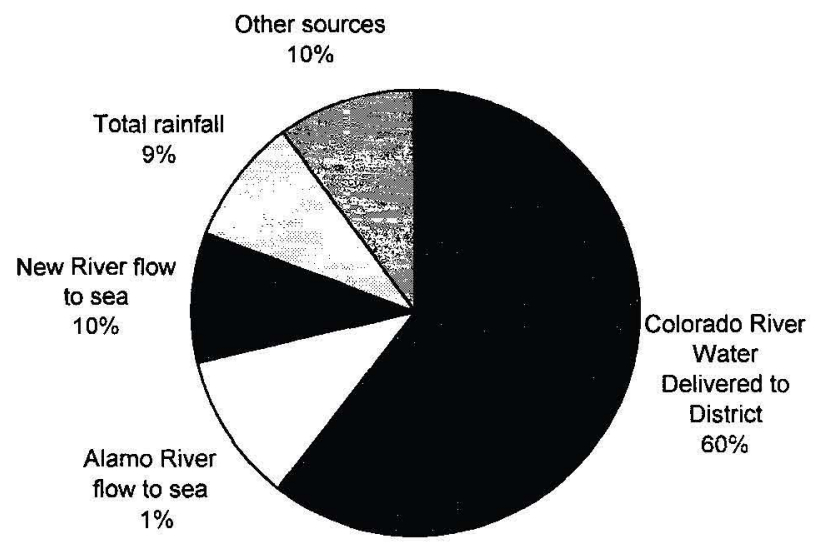

FIG. 5. Variance Components for Consumption of Irrigation Water on Irrigated Land (See Tables 2-6) 
TABLE 15. Quantities Used to Determine Irrigation Water Not Consumed, Example 2

\begin{tabular}{|c|c|c|c|c|c|}
\hline $\begin{array}{c}\text { Category } \\
\text { (1) }\end{array}$ & $\begin{array}{c}\text { Volume } \\
\left(1,000 \text { dam }^{3}\right) \\
(2)\end{array}$ & $\begin{array}{c}\text { Confidence } \\
\text { interval } \\
(\%) \\
(3) \\
\end{array}$ & $\begin{array}{c}\text { Standard deviation } \\
\left(1,000 \text { dam }^{3}\right) \\
(4)\end{array}$ & $\begin{array}{c}\text { Variance } \\
\left(1,000 \text { dam }^{3}\right)^{2} \\
(5) \\
\end{array}$ & $\begin{array}{c}\text { Variance used } \\
\left(1,000 \text { dam }^{3}\right)^{2} \\
(6) \\
\end{array}$ \\
\hline $\begin{array}{l}\text { River inflows from Mexico } \\
\text { Total rainfall } \\
\text { Other surface inflows } \\
\text { Subsurface inflow } \\
\text { Alamo River outflow } \\
\text { New River outflow } \\
\text { Direct flow to Salton Sea } \\
\text { Subsurface outflow } \\
\text { Canal and reservoir evaporation } \\
\text { Consumption by M\&I users } \\
E T \text { from rivers, drains, and phreatophytes } \\
\text { Rainfall evaporation from nonirrigated land } \\
\text { Effective precipitation } \\
\text { Noneffective rainfall evaporation } \\
\text { Canal and reservoir ET } \\
\text { Irrigation water contribution to } E T \text { from rivers, and so on } \\
\text { M\&I deliveries } \\
\text { Total }\end{array}$ & $\begin{array}{r}205 \\
102 \\
2 \\
16 \\
-415 \\
-400 \\
-80 \\
-2 \\
-24 \\
-40 \\
-73 \\
-13 \\
-52 \\
-23 \\
24 \\
52 \\
52 \\
-667\end{array}$ & $\begin{array}{l} \pm 10 \\
\pm 30 \\
\pm 30 \\
\pm 30 \\
\pm 8 \\
\pm 8 \\
\pm 10 \\
\pm 40 \\
\pm 20 \\
\pm 20 \\
\pm 20 \\
\pm 20 \\
\pm 20 \\
\pm 20 \\
\pm 20 \\
\pm 29.0 \\
\pm 5 \\
\pm 9.7\end{array}$ & $\begin{array}{r}10 \\
15 \\
0 \\
2 \\
17 \\
16 \\
4 \\
0 \\
2 \\
4 \\
7 \\
1 \\
5 \\
2 \\
2 \\
8 \\
1 \\
32\end{array}$ & $\begin{array}{r}105 \\
235 \\
0 \\
6 \\
276 \\
256 \\
16 \\
0 \\
6 \\
16 \\
53 \\
2 \\
27 \\
5 \\
6 \\
57 \\
2\end{array}$ & $\begin{array}{r}105 \\
235 \\
0 \\
6 \\
276 \\
256 \\
16 \\
0\end{array}$ \\
\hline
\end{tabular}

TABLE 16. Calculations for Fraction of Irrigation Water Not Consumed, $(1-I C U C)$, Example 2

\begin{tabular}{c|c|c|c|c}
\hline \hline $\begin{array}{c}\text { Category } \\
(1)\end{array}$ & $\begin{array}{c}\text { Volume } \\
(1,000 \\
\left.\text { dam }^{3}\right) \\
(2)\end{array}$ & $\begin{array}{c}\text { Relative } \\
\text { confidence } \\
\text { interval } \\
( \pm 2 C V) \\
(3)\end{array}$ & $\begin{array}{c}\text { Coefficient } \\
\text { of } \\
\text { variation } \\
(4)\end{array}$ & $\begin{array}{c}\text { Coefficient } \\
\text { of } \\
\text { variation } \\
\text { squared } \\
(5)\end{array}$ \\
\hline $\begin{array}{c}\text { Unconsumed irriga- } \\
\text { tion water }\end{array}$ & 667 & \pm 0.097 & 0.048 & 0.0023 \\
$\begin{array}{c}\text { Total irrigation water } \\
\text { supply }\end{array}$ & 2,107 & \pm 0.037 & 0.019 & 0.0003 \\
$1-I C U C$ & 0.317 & \pm 0.104 & 0.052 & 0.0027 \\
\hline \hline
\end{tabular}

ties are directly related, accounting for the dependence may be easy, as was the case for the beneficial uses in Example 1. However, in other cases, the interdependence is not as straightforward. Further examples on the influence of component interdependence are given in Appendix I.

Furthermore, independent components typically lead to narrower confidence intervals when components are added, as shown by Example 1, where the confidence interval went from \pm 8.0 to $\pm 8.6 \%$ when the dependence of components was considered. Thus, we recommend that independent estimates of each component in the water balance be made, if possible. In some cases multiple independent estimates of a water use of water-balance component may be available. However, for calculating the confidence interval of the performance parameters, dependence may actually improve the estimate, as shown in Example 2. The statistical procedures for dealing with these situations may still need improvement.

\section{CONCLUSIONS}

This paper underscores the importance of properly defining the components in a water balance when attempting to arrive at irrigation performance measures. The equations provided herein can be used to determine the accuracy of these irrigation performance measure estimates, based on the accuracy of the water-balance components. The examples given provide some practical guidance on the use of these procedures. In addition, it is shown that the component variances can be used to determine which measured volumes need closer attention. Improving the accuracy of those components with the highest variances will have the greatest impact on improving the accuracy of the performance measures. Finally, we recommended that studies that report irrigation performance mea- sures also provide estimates of the confidence intervals of these parameters so that inappropriate conclusions are not drawn.

\section{ACKNOWLEDGMENTS}

The writers would like to gratefully acknowledge the contributions of the Technical Working Group for the Water Use Assessment of the Coachella Valley Water District and the Imperial Irrigation District organized by the Lower Colorado Region of the Bureau of Reclamation. The writers would also like to express appreciation for the funding provided by the districts and the Bureau. The members of the group in addition to the writers were Steve Jones, U.S. Bureau of Reclamation, Boulder City, Nev.; Marvin Jensen, Consultant, Fort Collins, Colo.; Ken Solomon, Professor and Head, BioResource and Agricultural Engineering Department, California Polytechnic State University, San Luis Obispo, Calif.; and Joe Lord, Consultant, Fresno, Calif.

\section{APPENDIX I. INFLUENCE OF DEPENDENCE ON VARIANCE ESTIMATES}

It is well known that random errors in measurement can be reduced by repeated sampling. For example, if a single measurement has a random error of $10 \%$, then averaging five measurements reduces the error to $10 \% / \sqrt{ } 5$, or $4.5 \%$. The same principle applies to components in the volume balance; the more independent measurements that are needed to estimate the volume for a component, the smaller is the variance of the estimate. Suppose we have two independent variables ( $y_{1}$ and $y_{2}$ ) that add (or subtract) to determine another $\left(y_{0}\right)$. Suppose $y_{1}=50, y_{2}=50$, and $y_{0}=100$. If the standard deviations of $y_{1}$ and $y_{2}$ are both 5 , then by (6), the standard deviation of $y_{0}$ is $5 \times \sqrt{ } 2=7.07$. The coefficients of variation for $y_{1}$ and $y_{2}$ are both $10 \%$, while $C V_{0}=7.07 \%$. Note that the value of $s_{0}$ does not depend on whether the components are added or subtracted; however, the value of $C V_{0}$ does [i.e., it depends on $\left.m_{0} ;(8)\right]$.

If two parameters are dependent, it is necessary to estimate the covariance, $s_{12}^{2}$. The covariance indicates how well the two parameters are correlated. It can be estimated from

$$
s_{12}^{2}=\rho^{2} s_{1} s_{2}
$$

where $\rho^{2}=$ correlation coefficient (e.g., $R^{2}$ from linear regression with 0 intercept). Note that we have ignored higher-order terms in these equations (e.g., higher-order terms in polynomial regression). Suppose that in the above example, $y_{1}$ and $y_{2}$ are perfectly correlated, or $\rho^{2}=1$. Then $s_{12}^{2}=s_{1} \times s_{2}$. Applying (6), we find that $s_{0}^{2}=5^{2}+5^{2}+2 \times 1^{2} \times 5 \times 5$ 
$=100$. This gives $s_{0}=10$ and $C V_{0}=10 \%$. Now the accuracy of the sum is not influenced by the fact that two correlated variables were used to determine its value.

Clearly, many of the components in the volume balance influence each other. But, here, we are dealing not with whether or not the variables are dependent on one another, but whether the estimate for one variable is dependent on the estimate for another. Even so, estimating this dependence is tricky. One might expect that $E T_{c_{i w}}$ is well correlated with the net project irrigation water supply due to the volume balance procedure (Table 5). However, if the latter increases by $10 \%\left(61.3 \mathrm{~m}^{3}\right)$, the former increases by 61.3 over 390 , or $15.7 \%$. An estimate for $\rho^{2}$ was obtained by solving for project IE (Table 16) and its $C I$ without the intermediate calculation of $E T_{c_{i \omega}}$ (i.e., $C I$ was $\pm 13.7 \%$ ). Ignoring the correlation gave $C I= \pm 15.6 \%$. To obtain the same estimate for the $C I$ (i.e., $\pm 13.7 \%$ ) from $(13)$ and $(26)$ required $\rho^{2}=0.45$. (This is close to the ratio of the values squared.)

\section{APPENDIX II. REFERENCES}

Burt, C. M., et al. (1997). "Irrigation performance measures: efficiency and uniformity." J. Irrig. and Drain. Engrg., ASCE, 123(6), 423-442. Jensen, M. E., Burman, R. D., and Allen, R. G., eds. (1990). "Evapotranspiration and irrigation water requirements." ASCE Manuals and Reports on Engineering Practice, American Society of Civil Engineers, New York, N.Y., No. 70.

Ley, T. W., Hill, R. W., and Jensen, D. T. (1994). "Errors in PenmanWright alfalfa reference evapotranspiration estimates. I: Model sensitivity analysis." Trans. ASAE, 37(6), 1853-1861.

Mood, A. M., Graybill, F. A., and Boes, D. C. (1974). Introduction to the theory of statistics, McGraw-Hill Inc., New York, N.Y.

Pritsker, A. A. B. (1986). Introduction to simulation and slam II, 3rd Ed., John Wiley \& Sons, Inc., New York, N.Y.

Rhoades, J. D. (1974). "Drainage for salinity control." Chap. 16 in Drainage for agriculture, Agronomy Monograph No. 17, American Society of Agronomy, Madison, Wisc.

Styles, S. W. (1993). "On-farm irrigation efficiency." Spec. Tech. Rep. for Imperial Irrigation District, Boyle Engineering Corp., Imperial, Calif. 